\title{
Complete removal of pathogenic bacteria from drinking water using nano silver-coated cylindrical polypropylene filters.
}

\begin{abstract}
An attempt was made to investigate the removal of Escherichia coli bacteria from drinking water using nano silver-coated polypropylene water filter. For the production of nano silver filters, a modified Balzers 760 machine equipped with an electron beam gun was used. The nano-silver particles were made by electron beam bombardment of the silver metal, which were subsequently deposited on the polypropylene filters evenly. The thickness of the nano layer coated on the filters was $35.0 \mathrm{~nm}$. The nano silver-coated filters were characterized using scanning electron microscopy, X-ray diffraction, transmission electron microscopy, and atomic force microscopy. The antibacterial efficiency of the filters was evaluated using the membrane filter method. At a flow rate of $3 \mathrm{l} / \mathrm{h}$, the output count of E. coli was zero after $7 \mathrm{~h}$ filtration when the input water had a bacterial load of 103 colony-forming units (cfu) per milliliter. The inductively coupled plasma/mass spectrometry (ICP/MS) results showed that the $35 \mathrm{~nm}$ layer of the silver nanoparticles were stable on the water filter and were not washed away by water flow even after $72 \mathrm{~h}$.
\end{abstract}

Keyword: AFM; ICP/MS; Nano silver; SEM; TEM; Water treatment; XRD. 